\title{
LA AGROINDÚSTRIA DEL LIMÓN EN EL VALLE DE TECOMÁN, MÉXICO: UN ENFOQUE ANTROPOLÓGICO
}

\author{
Rosângela Azevedo Corrêa ${ }^{1}$
}

El mundo en el que vivimos actualmente no está constituido por naciones aisladas; por el contrario, se asiste a un proceso de globalización en el cual las conexiones sociales, políticas, económicas y culturales sobrepasan las fronteras territoriales. Las políticas de los gobiernos están cada vez más interconectadas, y a la vez sometidas, por las decisiones que emanan del Fondo Monetario Internacional o del GATT, mientras que, por otra parte, deben ajustarse a los acuerdos que derivan de su integración en estructuras supranacionales como el Tratado de Libre Comercio entre México, Estados Unidos y Canadá, o la Unión Europea. Esta situación, que ya muchos analistas definen como de un régimen de control internacional, pone en cuestión hasta dónde llega la autonomía efectiva del Estado nacional (Finkel, 1994: 335).

Según Roseberry (1991), se "necesitan prestar especial atención a las complejas interacciones de las presiones externas y las respuestas internas a lo largo del tiempo". ¿Qué elementos de la situación local deben ser entendidos en términos de las relaciones locales y cuáles de ellos en términos de fuerzas mayores? El propósito de la presente ponencia es explicar la vinculación de la agroindustria del limón en el valle de Tecomán, Colima con el sistema económico mundial a partir de la investigación realizada desde una perspectiva antropológica.

\section{El sistema economico mundial}

En la década de los sesenta y setenta se crea toda una discusión acerca de la dependencia y las perspectivas del sistema mundial, y provinieron de campos ajenos a la antropología pero con importantes implicaciones para el estudio antropológico de los campesinos. Los autores no partieron del poblado campesino, de manera que la comprensión de la vida aldeana no fue elegida entre sus problemas, sino que intentaron explicar el origen y la persistencia del atraso o subdesarrollo económico con el argumento de que el atraso era un producto directo del desarrollo del capitalismo.

Los autores que manejaron esta teoría partian de que los supuestos básicos de la

\footnotetext{
${ }^{1}$ Universidade de Brasília, Brasil.
} 
perspectiva del sistema mundial eran:

a) El científico social debería estudiar conjuntos sociales. En el mundo moderno, existe sólo un conjunto social: el "sistema mundial";

b) El sistema mundial está integrado económica más que políticamente. Esto es, se trata de una economía mundial compuesta por numerosos Estados políticamente independientes pero económicamente interdependientes;

c) El sistema mundial está diferenciado económicamente, y lo componen de un centro, constituido por los Estados desarrollados de la economía mundial (Estados Unidos y Europa Occidental, por ejemplo); una periferia, constituido por los Estados subdesarrollados del así llamado Tercer Mundo (Bolivia, Jamaica y Honduras, por ejemplo); y una semiperiferia, compuesta por Estados amortiguadores que disponen de mayores oportunidades de desarrollo que los Estados periféricos y ejercen cierto grado de influencia económica sobre sus vecinos, sin embargo no forman parte del "centro" (México, Venezuela, Sudáfrica y diversos países mediterráneos y de Europa del Este);

d) Esta desigualdad internacionalmente estructurada es un producto histórico de profundas raíces, creado con la formación de una economía mundial capitalista en el siglo XVI y perfeccionado a lo largo de cuatro siglos de cambios coloniales y poscoloniales. Las áreas o países semiperiféricos, considerados como un elemento estructural en la economía mundial, se encuentran entre el centro y la periferia desde el punto de vista de una serie de dimensiones, tales como la complejidad de las actividades económicas, la fuerza del aparato estatal, las formas de control sobre el trabajo, la integridad cultural, etc. Su función es sobre todo política, puesto que mantienen la estabilidad del sistema mundial. Los países centrales se caracterizan por un aparato de Estado fuerte mientras que los países periféricos cuentan con un Estado débil;

e) Los procesos sociales en regiones particulares sólo pueden ser comprendidos en términos del lugar y función de esas regiones dentro del vasto sistema mundial. Es ciertamente común que los teóricos del sistema mundial expliquen los problemas de la periferia o semiperiferia remitiéndose a dos factores: el desarrollo obtenido en el centro o los requerimientos para mantener el sistema como conjunto; 
f) El enfoque de Wallerstein es dinámico, en el sentido de que las naciones y áreas pueden cambiar su posición en el sistema mundial. Las áreas periféricas pueden llegar a formar parte de la semiperiferia y los Estados centrales pueden convertirse en semiperiféricos.

¿Cuáles son los mecanismos que permiten el paso de la periferia a la semiperiferia? Wallerstein (1976) señala tres posibles vías de desarrollo:

a) la estrategia de aprovechar la oportunidad de desarrollar políticas claves, como por ejemplo, la industrialización vía la sustitución de importaciones, en momentos en que los países centrales atraviesen una fase de debilidad;

b) la estrategia de invitación, que fundamentalmente consiste en atraer inversiones de corporaciones multinacionales;

c) la estrategia del desarrollo de la confianza en el propio país, con políticas claramente definidas.

El otro tránsito posible dentro del sistema mundial es el paso de semiperiferia al centro que se da cuando un país cuenta con un mercado interno que justifique la existencia de una tecnología avanzada.

Si se considera seriamente esta perspectiva, no parece dejar lugar a la antropología que practica la mayoría de los antropólogos. Con todo, muchos de los antropólogos que la han tomado en serio no han dejado de cuestionar algunos de los postulados fundamentales de la perspectiva del sistema mundial. La gente con la que vivimos y sobre la que escribimos generalmente vive en la periferia o en la semiperiferia del sistema mundial de Wallerstein $(1974,1979)$. Cuando el precio de sus productos se viene abajo en los mercados mundiales, cuando las corporaciones extranjeras se apoderan de sus tierras o cuando otros inversionistas extranjeros abandonan lo que a una vez fue una región próspera y activa, el centro capitalista influye profundamente en las regiones periféricas y en los pueblos que viven en ellas.

Roseberry (1991) afirma que también percibimos otros aspectos importantes de la vida económica, social y cultural que no pueden ser explicados en términos de centro. 
Advertimos vigorosos sistemas de comercialización regional en los que circulan mercancías localmente producidas. En ciertas ocasiones, y bajo condiciones que no le es dado elegir, advertimos que la gente de la localidad adopta una amplia diversidad de formas de resistencia frente a las demandas del capital local y extranjero. Roseberry opina que percibir a los campesinos como parte de un mundo vasto, y explicar todo en términos de las necesidades o dinámicas del centro capitalista o del sistema en su conjunto es profundamente funcionalista y reductivo.

Esta perspectiva del sistema mundial ofrece una buena cantidad de dilemas metodológicos al antropólogo. El primero de ellos se refiere al nivel o unidad de análisis adecuados. ¿Cómo puede uno hablar acerca de regiones locales en términos de factores locales, nacionales e internacionales sin perder el control metodológico? La solución de Wallerstein - de que uno estudia sistemas sociales en su conjunto y en consecuencia debe concentrarse en el sistema mundial mismo - no le concede espacio a la antropología. En un principio presté atención a la región local e intenté decir algo sobre las relaciones locales y extralocales, así como de fuerzas sociales. Sin embargo, me enfrenté a una deformación metodológica; cuando estudiamos en comunidades y consideramos el efecto de los fenómenos nacionales y globales, nos preguntamos qué elementos de la situación local deben ser entendidos en términos de las relaciones locales y cuáles de ellos en términos de fuerzas mayores. Cuando nos hacemos estas preguntas, solemos partir de un modelo espacial implícito o explícito que se mueve de las comundidades a las regiones, de éstas a las naciones, y de ahí al mundo.

\section{El problema de la perspectiva regional}

Debido a la naturaleza de las preguntas que se hace a la sociedad mexicana, la antropología social ha debido emprender estudios de regiones. Según de la Peña, el concepto de región ha tenido mayor nitidez y utilidad cuanto más nítidamente ha logrado el antropólogo articular su problemática teórica (1991:156).

El estudio sobre la región del Acolhuacan realizado por Palerm $(1954,1955)$ coincidente con el territorio del antiguo señorio de Texcoco, que se extiende al occidente del valle de México - ha marcado el inicio de estudios regionales en la Universidad Iberoamericana. Su interés era descubrir la lógica de las transformaciones en esta región, que se presentaba diferenciada en términos culturales, ecológicos y económicos tanto internamente como respecto del resto del valle de México, donde ha 
florecido por diez siglos la concentración del territorio mexicano.

Palerm siguiendo a Luxemburgo, afirmaba que la formación del sistema mundial capitalista en el siglo XVI es el punto de partida del análisis regional; el sistema no tiene un efecto homogeneizante sino diferenciador. El interés diacrónico del antropólogo, le permite explotar la importancia de la organización previa al sistema capitalista en la determinación territorial.

Posteriormente Palerm afirmó que la región es algo más que un nivel entre la nación y sus instituciones por un lado, y la comunidad local por el otro. Una región se define esencialmente por la problemática establecida después de un proceso de investigación realizado en función de los objetivos que se trata de conseguir. La región puede coincidir, pero no tiene que hacerlo necesariamente, con un área definida por criterios geográficos, culturales, políticos o económicos. Palerm afirma que "es el problema o conjunto de problemas que se plantean en concreto, aquello que permite establecer los límites y la extensión de la región. Por otra parte, la región va adquiriendo realidad en el transcurso mismo de la acción transformadora" (1993: 325).

La zona agrícola en el valle de Tecomán, lugar de la presente investigación, no es sólo lugar de residencia sino también un lugar de trabajo; esto me obligó a ver a la región de Tecomán, y a buscar una definición de región. No existe un claro consenso sobre qué es una región ni sobre cuáles son sus elementos constitutivos. La región puede ser un territorio delimitado por elementos naturales, como una cuenca hidrológica, o político-administrativos, por razones de dominio o de planificación. Pero prefiero que la región sea definida a través de la identificación de un producto comercial y orientado al mercado y que une la región con la sociedad mayor tal como lo hizo Torres $(1986,1991)$ para el caso de la producción de tabacos claros en una sociedad rural ilocana en Felipinas. Su estudio de un cultivo comercial predominante en un área rural le llevó a una plena caracterización socio-cultural de la misma. El proceso social no para en las fronteras físicas; el campo social suele expandirse más allá del territorio. La autora afirma que el punto de partida fue la observación sistemática del territorio en donde se ubica la sociedad a ser estudiada; lo que ella observó fue un medio culturalmente creado en el que se han realizado transformaciones a través del tiempo con tecnologías específicas por medio de arreglos sociales específicos. 
Torres afirma que:

La descripción del espacio se vuelve relevante para el investigador social cuando se advierte en él, la forma en que los grupos humanos invierten su conocimiento, desarrollan una organización del trabajo y utilizan un complejo tecnológico para llevar a cabo su proyecto de vida.

El territorio, visto como fenómeno social, conlleva un orden cultural y social de las acciones que en él se realizan.

(Torres, 1991: 139-140).

Por esta razón, la principal decisión metodológica en el valle de Tecomán fue la de concentrarse en el limón; y fue sumamente útil porque el investigador trata con un bien producido localmente pero intercambiado en los mercados mundiales. El limón era el principal medio de integración entre la región, la nación y el mundo a partir de la década de los cincuenta. Además, la mayor parte de los derivados industriales tienen mercado en el exterior; la cantidad de fruta disponible para la industria fluctua dentro de límites muy amplios y, a menudo es afectada por las políticas del mercado lo que ocasiona períodos de auge y crisis severas en el sector.

El estudio se concentró en la relaciones entre los productores, industriales, jornaleros agrícolas, obreros, empacadores y "coyotes" (intermediarios locales) de la región, combinando la observación- participante al interior de las fábricas y parcelas con entrevistas a las autoridades políticas locales y estatales. Con todo, el estudio no abordó la perspectiva mundial con el mismo detalle. No fueron explorados los archivos de la transnacional que se encuentra en la región ni sus relaciones con la corporación a la cual pertenece y su relación con el mercado internacional.

Pero meterse a la fábrica, ver cómo producen los obreros, cómo actúan y se relacionan entre las máquinas e instrumentos de trabajo, salir con ellos, encontrar con sus parientes o vecinos que venían del campo, transitar conjuntamente sus trayectos, vivir en sus mismos hogares y convivir con ellos y sus familias para enfrentar sus necesidades básicas de sustento, casa y vestido; "no agregaron aspectos sino que los interconectaron en un todo para hacerlo entendible. Las técnicas antropológicas siguen siendo una garantía para descubrir datos y apuntalar interpretaciones retadoras" (Alonso, 1993: 83). Lo que constituye una investigación antropológica, muchas veces se supone que el micro-análisis es la característica que la define pero ella sólo no hace el estudio antropológico. Nuestro principal aporte como antropólogos es la manera de realizar la investigación. El análisis a nivel micro inicia y se ubica en el contacto directo con la realidad y carece de las 
posiciones de representatividad que dan los agregados estadísticos. Sin embargo, como lo apunta Bueno, estos estudios permiten detectar procesos que ni los economistas ni los ingenieros han podido observar y dan cuenta de la conducta social de los sujetos involucrados; "esto es, del cómo y porqué existen regularidades en la manera de trabajar, de ingresar y de permanecer en el lugar de trabajo" (1994: 27).

Este estudio intenta hacer aportes sustantivos, teóricos y metodológicos. En el primer aspecto, busco profundizar en las transformaciones que se están dando en diferentes ámbitos de la realidad mexicana: los mercados de trabajo, las familias, las relaciones entre ejidatarios, propietarios privados, industriales y obreros. En esta perspectiva, la observación-participante desde el piso de trabajo, me permitió ver la influencia de los cambios macroestructurales sobre la región con una tradición exportadora y, puntualizar la relevancia de la percepción de los actores, sus acciones y decisiones. Seguiendo la orientación de Torres, "el observar al trabajador en el contexto de trabajo, alrededor de la máquina, del supervisor, los techos, ruidos, uniformes, presiones de tiempo, de compañeros; al considerar las presiones que reciben los trabajadores en la fábrica tanto de fuera y como de dentro, me informa sobre el tipo de sociedad que se genera en este proceso peculiar de producción" (1993: 18).

Las técnicas clásicas de trabajo de campo antropológico también pueden ser de gran utilidad, por más que no parezcan muy compatibles con una perspectiva del sistema mundial. Utilicé historias de vida que es un método especialmente útil para trascender las muy delimitadas unidades espaciales y detectar los cambios ocurridos con el paso del tiempo; así como genealogías y estudios de caso.

Cuando yo llegué a Colima, pregunté sobre que tipos de industrias había en el estado instalados en el campo; lo primero que me informaron fue la importancia de la agroindustria del limón en el Valle de Tecomán. Según el Instituto Nacional de Investigaciones Agrícolas-SARH (1981), la actividad agrícola del limón en el estado de Colima ocupó 1.5 millones de jornales anuales que benefició a 10,000 familias rurales, sin incluir el costo de mano de obra de obreros y empleados que laboran en las industrias afines: empaque, fábricas, fertilizantes, plaguicidas y material de empaque. 


\section{Descripcion del área de estudio}

Para llegar al Valle de Tecomán², salimos de la carretera de Colima rumbo a las playas localizadas hacia el oeste. Politicamente, pertenece al Estado de Colima y concentra a los municipios de Manzanillo, Coquimatlán, Tecomán y Armería; yo sólo estudié a los dos últimos municipios debido a su mayor concentración del limón.

Geográficamente, este valle está formado por el río Armería que viene desde la cadena montañosa de la Sierra Madre occidental, en su último tramo recorrido hacia el mar. Se atribuye al municipio de Tecomán una superficie de $808 \mathrm{~km}$ y tiene dos zonas definidas: la costera que es una franja con el 60\% de la superficie total, con $30 \mathrm{~km}$ de litoral, $17 \mathrm{~km}$ en su parte más ancha tierra adentro y $8 \mathrm{~km}$ la más angosta, estimándose en 487 kms; y la planicie costera conocida como el Valle de Tecomán, que se puede dividir en zonas geográficas:

a) la costa: explotada por los pescadores, fue lugar de numerosas salinas como Pascuales, El Real, Tecuanillo, Carrizal, Manzanilla, Guazango, El Coco, Guayabal que al inicio del presente siglo representaba la principal fuente de ingreso para la población local, sobre todo indígenas que era la principal mano de obra para la extracción de la sal. También es lugar de recreación de la población local; casi no llegan turistas nacionales o extranjeros a sus hoteles debido a la cercanía de Manzanillo que está a menos de una hora de Tecomán. Rumbo a la playa de Tecuanillo hay un criadero de langostinos en diez hectáreas del Rancho Los Desmontes donde llevan casi diez años en la investigación para hacer el negocio rentable.

b) la planicie costera donde quedan solamente pequeñas porciones arboladas del tiempo de antaño. La gente recuerda que en la época del ganado, había hasta madera para la construcción como la caoba macho (que es más duro y no florea como la hembra), el moralete, solocaye, balsamo, granadillo, camotillo (color blancoso); otras maderas era la primavera, la parota, la rabelero, palo-fierro (que es muy duro, que si no sabe trabajar, se rompe la hacha). Debido al aprovechamiento que se ha hecho de la tierra para fines

\footnotetext{
${ }^{2}$ En 1523, Gonzalo de Sandoval llega al Valle de Tecomán, y "en uno de los parejas más fértiles (Caxitlán) decidió fundar una villa que serviera de capital al reino de Colimán. Al informarle a Cortés de todo lo ocurrido, le hace notar lo insaluble del lugar y lo extremoso del clima; éste le da la orden que se buscara un lugar que fuese bueno y llegan al Valle de Colima. La fundación de Tecomán en 1523 se debió a la conveniencia de los españoles de controlar a los indígenas, obligándoles a concentrarse y fundar un
} 
agrícolas há cambiado el paisaje. Podría decirse que la parte del valle fue reforestada con las plantaciones de palmares y frutales. El valle está cubierto por cultivos en su totalidad. Resalta de inmediato la importancia del limón ${ }^{3}$, debido a la gran cantidad de héctareas dedicada a él en el valle, y entre los limonares hay también cocotales, en algunos casos, en forma mezclada, como si el limón creciera a la sombra de las palmeras. Hay otros cultivos de árboles frutales como el mango, guanábana, plátano, tamarindo. Si la vista se detiene a los pocos cultivos anuales llama la atención el melón. Pero lo que casi no hay es el maíz o el frijol, cultivos tradicionales del campo mexicano para el autoconsumo.

La carretera nacional que cruza el valle de norte a sur nos obliga a ver la predominancia del limón sobre los demás cultivos. Hay grandes construcciones a manera de bodegas, empacadoras, con básculas para camiones cuyos letreros indican que compran el limón. Si uno visita la región en mayo, la actividad es impresionante. Camiones de carga de todos los tipos y tamaños que llevan o van por limón. Si uno visita el valle en enero, época de melones, la actividad es mucho menor que comparada con la temporada del verano.

Aún más, hay fábricas en este valle agrícola, y son fábricas dedicadas al limón. Van desde simples seleccionadoras y empacadoras de la fruta a instalaciones en donde se obtienen jugos y aceites del limón hasta otra, mucho más sofisticada en donde se obtienen pectinas a base de la cáscara del limón, de hecho usa tecnología de punta con una planta totalmente moderna a partir de 1992. Las construcciones industriales, van al lado de las plantaciones dejando los pocos asentamientos urbanos distantes.

En la cabecera municipal de Tecomán y Armería predominan dos tipos de asentamientos urbanos: un tipo de construcción tradicional que consta de un armazón de madera dura con paredes de pajarete y techo de palapa; estas habitaciones se encuentran en las colonias a las afueras de la cabecera donde viven los jornaleros agrícolas, en su mayoría, en condiciones deplorables y constituyen 120 vecindades en total. Otro tipo de asentamiento es un tipo de construcción de casas de ladrillo y teja, donde viven los trabajadores (obreros, personal de confianza y administradores de las fábricas) y algunos

pueblo del cual denominaron "Santiago Tecomán". Tecomán nació como un pueblo autóctono y siguió siendolo hasta fines del siglo pasado.

${ }^{3}$ El limón mexicano o lima ácida (Citrus Médica L., variedad o citrus aurantifolius), botánicamente es una lima ácida, cuyo origen se remonta a la India Oriental, principalmente en las estribaciones del Himalaya o en la India Central. Según Tolstowski, el origen del limón mexicano proviene del archipielago Malayo; es también abundante en las Islas del Sur, en el Oceano Pacífico, Tahití y Filipinas. 
agricultores.

Considerando que en Tecomán la población es mayoritariamente joven; el marco familiar de muchas familias pobres está caracterizado por el alcoholismo, drogadicción, prostitución, desintegración en las colonias más marginadas de la cabecera municipal con calles terregosas, mal trazadas, casas construídas con venas de palma y población hacinada, lo que ha provocado que encontremos un mayor porcentaje de robos, lesiones y homicidios del estado.

En estas vecindades hay una carencia de servicios públicos y una ausencia de políticas municipales y estatales para considerar esta situación, y crear programas de atención a los niños y los adolescentes de las familias marginadas de Tecomán. Algunas acciones que existen por parte de la iglesia católica o de la Casa Hogar del Niño Tecomense son asistencialistas, sin cuestionar las estructuras socioeconómicas y políticas de esta problemática. En el discurso de muchos productores, los niños trabajan por culpa de sus padres que se lo permite, aunque ellos no recriminan que estos niños ayuden a sus padres en las labores del campo. Los municipios colimenses de Ixtlahuacán, Armería y Tecomán son los que presentan los porcentajes más bajos de asistencia escolar entre la población de 5 a 14 años de edad debido al trabajo infantil en los huertos agrícolas de la región. La mayoría de estos padres trabajan en la agricultura pero necesitan también de otras opciones de trabajo que pueden ser concomitantes con el trabajo agrícola como la albañileria, pequeño comercio, pesca, etc. Pocos llegan a ser ejidatarios, la mayoría trabajan como jornaleros agrícolas.

La expropiación de los terrenos de la comunidad indígena de Tecomán currió el 18 de enero de 1885, habiendo sido dividida em 240 lotes que conforme el informe del gobernador Esteban García fueron sorteados entre los indígenas; estos lotes median 450 x 1000 metros que fueron adquiridos en su mayoría por el general Angel Martinez, quien era el mayor terrateniente del lugar y propietario de la hacienda Paso del Río con sus anexos. Los indígenas de Tecomán, sin tierras de cultivo, se convertieron en mano de obra para las haciendas, apesar de protestaren en contra del general Martinez por la pérdida de sus tierras comunales (Acuña, 1993: 31).

Esta región ha sido eminentemente rural, la población radicaba en los ranchos y haciendas, y los dueños de estas últimas vivían en Colima, visitando con frecuencia sus propiedades. La gran mayoría de la población, hoy en día, proceden de otros lugares de

Los datos históricos mencionan que tanto el limón como la naranja fueron introducidos por los españoles a las islas occidentales. 
Colima o llegaron de otras entidades federativas de la República, a partir de la década de los treinta, sobre todo de los estados de Jalisco y Michoacán. Hasta la década de los cincuenta se crearon nuevos ejidos en el municipio de Tecomán; se puede decir que durante las décadas de los treinta y los cuarenta, la mayor parte del municipio pertenecía a particulares. Actualmente, en el estado existen 289, 291 hectáreas repartidas en 147 ejidos de los cuales 19 se encuentran en Tecomán, cubriendo una superficie de 30,243 hectáreas y ocupadas por 1,319 ejidatarios y 189, 544 hectáreas de propiedad privada lo que demuestra la concentración de la tierra en manos privadas (Inegi, 1988). La escasa presión sobre la tierra en Tecomán se puede explicar por la relación entre los agricultores foráneos con el gobierno en el centro del país, y la carencia de irrigación que no favorecía el valor de la tierra. La solicitud de dotación de ejidos provino más bien de gentes de otros estados como fue el caso del ejido Santa Rosa que eran originarios de Tamazula, Jalisco.

En 1930, el municipio de Tecomán tenía 7,151 habitantes mientras que para 1960 habían 23,877 habitantes y 1970 con 44,406 habitantes de los cuales 22,591 eran hombres y 21,815 mujeres, siendo que 27,382 eran colimenses, 16,970 eran procedentes de otros estados y 54 extranjeros, lo que nos da un 38\% de la población del municipio no es originaria del estado. En 1980 tenemos a 67,064 habitantes, y 1990 la población llegó a 82,699 habitantes siendo 25,646 de población no nativa. En cuanto al municipio de Armeria, su población en 1980 era de 21,847 habitantes y de 27,782 habitantes en 1990 (Inegi 1930, 1960, 1970, 1980, 1990). Tecomán concentra el 19,3\% de la población estatal y Armería el 6,5\%; la tasa de crecimiento del primer municipio es del 2,1\% y del segundo es del $2,5 \%$.

La población del estado de Colima es relativamente joven con un 37,9\% menores de 15 años de edad y sólo 4,6\% tienen 65 años o más. La población ocupada en cada sector económico representa un total de 133,474 personas en el estado; según el sexo, en 1990 nos indica una tendencia hacia el sector terciario con $42,3 \%$ de hombres y $80,7 \%$ de mujeres dedicadas a estas actividades; el 29,8\% de los hombres se dedican a la agricultura y $25,4 \%$ a la industria. La diferencia en relación a la participación de las mujeres es contrastante con un 5,9\% de las mujeres que se dedican a la agricultura y el $8,8 \%$ a la industria. En el censo consta que el 6,1\% de las mujeres son trabajadoras agropecuarias y el 93,9\% son hombres, aunque es común que las mujeres declaren que son amas de casa porque su trabajo en el campo es intermitente con sus quehaceres domésticos y las vacaciones de los hijos en la escuela que coinciden con la mayor producción del limón 
durante el verano, cuando varios miembros de la familia participan en la cosecha de esta fruta.

\section{Un estudio regional e histórico}

Desde los campos más usuales del estudio antropológico al de la industria, busqué entender las relaciones que son establecidas entre la comunidad y la fábrica. En una región agrícola/industrial resalta dos aspectos importantes: el trabajo en el campo y el trabajo en la fábrica, uno no desplaza al otro, sino que lo integra. El trabajo de Slotkin (1968) tiene una importancia especial para esta investiga- ción porque él analizaba la influencia de la fábrica en la sociedad que la rodea, donde se suele considerarse el lugar de residencia, aunque Slotkin nos da ejemplos de personas como los montañeses que no viven en comunidades compactas. Según este autor, la industrialización es en general una innovación fundamentalmente, y ella y sus ramificaciones tienden a producir una desorganización cultural y social por lo que se adoptan nuevas costumbres y se crean grupos para lograr una nueva integración cultural. El industrialismo es un conjunto de costumbres interdependientes; la gente adopta las innovaciones que parecen ser consistentes con su cultura pero frecuentemente rompe las tradiciones, las costumbres de siglos y los lazos familiares y cambia en general los sistemas de vida que acostumbraban los miembros de una comunidad, antes de la industrialización. Por lo regular, cuando surge una industria en una comunidad, ésta es llevada por gente ajena al área y a los miembros de la comunidad; éstos llegan con el capital a imponerse sobre los nativos su dominio económico.

Según Slotkin, la industrialización atrae inmigrantes lo que producirá una complejidad social y heterogeneidad cultural y los hacen enfrentarse a una comunidad diferente. El trabajador emigrante se vuelve más dependiente de su salario que de los grupos tradicionales para su adaptación, de manera que, aunque separados, la familia tiende a ser el grupo primario básico. Este autor considera que la industrialización genera cambios y reajustes en la comunidad completa, no sólo en los individuos que se involucran diretamente en el proceso de trabajo. El hecho que una persona forme parte de una organización industrial también influye en sus grupos y costumbres fuera del trabajo.

En la medida que iba conociendo más la región, me daba cuenta que las personas ocupaban lugares públicos como los restaurantes o la plaza y que ocupaban diferentes puestos de trabajo al interior de las fábricas o en el campo, al mismo tiempo que había 
una interdependencia de la producción agrícola en relación con la fabricación de los subproductos del limón. Las especificidades de la producción en el campo y la fuerte polarización de los estratos de los productores (un sector reducido de grandes empresarios y/o industriales frente a una constelación de pequeños propietarios y ejidatarios) me impulsaban a analizar las articulaciones sociales entre el campo y la fábrica. El carácter perecedero del limón incidirá en una determinada organización tanto laboral como social.

En un inicio, yo intentaba realizar un estudio sobre la relación comunidad-fábrica, siguiendo el modelo de Slotkin, dentro del proyecto dirigido por la Dra. Patricia Torres en la Universidad Iberoamericana y financiado por CONACYT, pero la región me rebasó. Me gusta las preguntas que Slotkin se hace pero no como las resuelve; yo no encontré una homogeneidad en el lugar de residencia porque la sociedad en el Valle de Tecomán fue creada y establecida a raíz de la agroindustria del limón, y cada actor social tiene una historia distinta, tanto los inversionistas como ejidatarios, administradores, jornaleros y obreros. De manera que necesité hacer la historia regional como lo hizo Roseberry (1991) en el distrito de Boconó en Venezuela; el valle cerrado constituyó una unidad económica y social por sí misma en una región en plena expansión.

Este estudio era regional e histórico, entendiendo la historia como el proceso de generación de una sociedad donde voy a resaltar los factores del trabajo. Me interesa la história de la gente del Valle de Tecomán a través del limón, su articulación en una agroindustria como un todo en el cual depende la vida de la gente de la región. Para eso partí de la historia de los cultivos para la conformación de la región a través de la interacción de los grupos sociales de ayer y hoy. No pretendo contar la historia de la región del Valle de Tecomán donde todo comienza y todo termina por el tiempo sino cómo las relaciones sociales que caracterizan un período o a un tipo de relación siguen teniendo peso social, económico y político en un período subsecuente. Una perspectiva histórica es fundamental en todo intento por colocar regiones particulares dentro del sistema mundial. Debería resultar claro que la naturaleza de la relación entre una región local y la economía mundial cambia con el tiempo.

Braudel dice que "presente y pasado se aclaran mutuamente, con luz recíproca", pues "ningún estudio social escapa al tiempo de la historia" (1984: 80-82). Las variaciones en la organización del trabajo que emergen a través de estudios comparativos e históricos pueden ser explicados únicamente si nos situamos fuera de la fábrica y examinamos su contexto variable, en particular los modelos de competencia entre capitalistas y las luchas entre capital y trabajo organizados por el Estado como lo ha 
propuesto Burawoy.

Una consecuencia adicional del enfoque histórico es la clara perspectiva que proporciona sobre los actores locales mismos. Con demasiada frecuencia los antropólogos discuten el peso relativo de los factores locales, regionales, nacionales e internacionales sobre la actividad de los campesinos, artesanos o comerciantes locales como si estos actores fuesen simples determinaciones históricas y estuviesen puestos a actuar en (y a ser influidos por) la situación presente. En el valle de Tecomán las propiedades privadas empezaron a surgir sólo con la formación de una economía de algodón y limón en la década de los treinta, después que la reforma agraria tuvo poco éxito en la región. Los agricultores que se metieron en la producción del limón o que llegaron para sembrarlo adoptaron un punto de vista cada vez más empresarial, pues contrajeron deudas y sembraron limón con otros cultivos (palma, mango, plátano) pero predominó el limón que era una mercancía de exportación. Las continuas crisis de la agricultura de la región están relacionadas sobre todo con este producto.

El estudio de una región me permitía ver que las fuerzas y las relaciones que afectan a la región se localizaban en otra parte, lo que resultaba necesariamente parcial el punto de vista del Valle de Tecomán. Para resolver el dilema metodológico era preciso transcender las metáforas espaciales. Ignorar la economía mundial y estudiar un terreno local sin tomar en cuenta el terreno no local puede permitir la preservación del rigor analítico, pero a expensas de la comprensión histórica. La propuesta de Roseberry es que para evitar esto, debemos concentrarnos en las relaciones que trascienden las fronteras espaciales, que toman la situación social aparentemente externa para convertirla en interna e incluirla en nuestro modelo. Como estudiamos en comunidades, tenemos que ser creativos en nuestra conceptualización y estudio de relaciones, instituciones y redes que se encuentran aparentemente fuera de la comunidad.

Por esta razón, estudié en detalle a dos fábricas que llamé de Emfrut y Pectec; el presente estudio no se quedó a nivel de comunidad, pero tampoco podía tomar a la industria como elemento central porque entonces sería un estudio clásico, en el campo de la antropología industrial, en el sentido de Lupton (1968) y Burawoy (1979) donde desde la fábrica parten. En una de las fábricas más importantes de la región, Emfrut, yo quería observar el impacto de la agroindustria del limón en la región a través de la comercialización de la fruta y de la industrialización del producto. En este sentido, mi interés era detectar cuáles habían sido los cambios que produjeron en las relaciones sociales a partir de las presiones competitivas del mercado, así como la resistencia de los 
trabajadores. El significado sociológico que se atribuye a la participación de los empleados y los obreros depende en buena medida de la perspectiva con que se analice la organización del trabajo. Para autores como Braverman, que insisten en la vigencia del taylorismo/fordismo, la implicación de los trabajadores en la vida de la empresa no modifica sustancialmente las tendencias a la degradación, sino que sólo representan una acomodación cosmética a las exigencias de un mayor control. En el otro extremo, para aquellos que consideran que el fordismo está históricamente agotado, las nuevas formas de organización del trabajo, no sólo facilitan, sino que exigen la participación y compromiso de los trabajadores.

La agroindustria del limón presenta un caso realmente interesante por su vida corta. Esto ha permitido observar la creación de una sociedad. Migrantes de diferentes partes del país, principalmente del occidente de México, son convocados al desarrollo del Valle de Tecomán. Capital y migrantes proporcionan los elementos básicos necesarios para lograr el desarrollo de esta agroindustria. Una fuerte ingerencia del gobierno federal a través de créditos y creación de infraestructura, sobre todo en obras hidráulicas y carreteras, lograron el desarrollo exitoso de Tecomán.

Al inicio de la década de los cincuenta, la competencia de la industria "Factor Mexicano", ubicado en la capital del estado, absorbía casi todo los desechos de la fruta de Tecomán, creó uma situación de insatisfacción por parte de los productores por el precio establecido en el mercado que para solucionar el problema deciden industrializar por cuenta propia su producto. También el Estado intervino directamente para organizar la oferta del aceite esencial, creando un sólo canal de comercialización y así solucionar una crisis en este período.

La base de las buenas relaciones entre los empresarios que migraron al Valle de Tecomán se manifestó en el reparto del poder local, y éstos se beneficiaron en forma notable con la política económica gubernamental, en particular de los créditos oficiales destinados a la inversión industrial; no se supo que hubiera ninguna competencia o conflicto realmente significativo en este período entre la inversión foránea y la local. La apertura de las tierras de cultivo en el Valle de Tecomán permitió la configuración de una organización agrícola para la expansión de cualquier actividad agrícola intensiva.

En la década de los setenta, el Estado mexicano interviene más fuertemente en la región para la producción, comercialización e investigación del limón, lo que dará pauta para la constitución de una empresa paraestatal, que denominaremos Emfrut para controlar la comercialización y manufactura del limón. También en esta década se dio la 
constitución del ejido Santa Rosa asi como de otra empresa de producción de pectina, Pectec, que tuvo su inicio con un empresario mexicano que frente a su incapacidad financiera la venderá al capital danés en la década de los ochenta.

La región, como espacio histórico-social concreto que está en constante proceso de formación y transformación, no son territorios pasivos; los largos procesos de reorientación y ajuste que se iniciaron en 1982 y continuaron en 1992 (momento de la investigación) ha llevado a una privatización en todos las empresas antes mencionadas. Los cambios impulsados por los gobiernos de Miguel de la Madrid, primero, y por Salinas de Gortari a partir de 1988, llevaron a que las transformaciones, bajo la denominación general de la "modernización", incluyeran en la reorientación de la economía hacia el mercado mundial, la desregulación económica, la reorganización financiera y la modificación de los papeles respectivos de empresarios y gobierno en la dinámica social.

Para analizar la organización del trabajo de la región fui a ver que es lo que pasaba en espacios cerrados como la parcela y la fábrica; en la primera fábrica (Emfrut), todos son asalariados hasta los administrativos; además está compuesta por socios pero con grandes diferencias de capital y poder entre éstos. En la segunda fábrica, Pectec, todos los empleados y obreros son asalariados y pertenecen a una transnacional que tiene presencia en los cinco continentes. En la parcela me encontré con asalariados agrícolas temporales, sin ningún contrato claro que trabajan para dos tipos de propietarios: a) propietario con su administrador y sólo asalariados; b) ejidatarios que administran y trabajan su tierra con alguna necesidad de ayuda en intercambio o con asalariados. Ambas empresas agrícolas están basadas en la anualidad de la cosecha del limón que debe darles de comer, aunque buscan complementar sus actividades en la misma región o emigran hacia Estados Unidos.

En la medida que avanzaba la investigación, observaba formas organizativas distintas y hasta competitivas: propiedad agrícola privada y ejidal, comercializadoras privadas y estatales, industrias empacadoras y manufacturas de propiedad individual y colectiva y una industria para la transformación química del producto con tecnología de punta (primero de capital nacional y después de capital internacional). Por esta razón decidí abordar cuatro formas específicas de organización del trabajo que se integra en la producción, industrialización y comercialización del limón: 
a) empresa agrícola familiar (ejidal): las relaciones son más horizontales, con una enorme flexibilidad de la mano de obra en función de la composición y la estructura de la familia que permite una enorme diversidad de actividades debido a la limitación de tierras impuestas por el Estado;

b) empresa agrícola de capital privado: el propietario tiene un administrador que se encarga de la supervisión de la producción y contrata básicamente mano de obra temporal;

c) las empacadoras que comercializan el limón fruta a nivel local y emplea a trabajadores así como contribuye a la existencia de los "coyotes" (intermediarios) que se relacionan directamente con los productores, tanto ejidales como privados, por la vía de la "informalidad". Los individuos que manejan estas empresas son empresarios porque asumen iniciativas encaminadas a obtener provecho mediante la manipulación sistemática de personas, recursos materiales y conocimientos (Bueno, 1995: 118);

d) empresas de transformación del limón: Emfrut, la primera, es una empresa de capital nacional, producto de un fideicomiso, que se transforma en sociedad anónima y las decisiones son tomadas por los socios con grandes diferencias de capital, siendo que los socios menos "poderosos" pueden ser asalariados (ellos o sus parientes). Además radican en la región, cultivan el limón y/o otros frutales y los subproductos de la empresa son vendidos casi en su mayoría en el mercado internacional. Aquí se da una situación muy peculiar donde los participantes de esta empresa, los ejidatarios, los staff administrativo, el mismo director trabajan como "dueños" de la planta, aunque no se ponen de acuerdo, todos en cierta forma, tienen interés en el éxito de la planta. Es el contexto internacional, al capital privado nacional, los políticos celosos o de otra postura, que quieren que fracase para quedarse con ella. Pectec es la segunda empresa, de capital transnacional, donde las decisiones son tomadas desde Europa y de acuerdo a los vaivenes del mercado internacional.

Los productores locales, ejidatarios y propietarios privados, venden el limón fruta a los "coyotes", a los empaques locales o directamente a las empresas como Emfrut. Las empresas locales producen los subproductos del limón: jugos, aceites y cáscara deshidratada; este último producto es la materia prima para producir pectina que será elaborada por la única empresa en México que es Pectec. Pectec también compra su 
materia prima en otros lugares de la República como Oaxaca, Michoacán y Veracruz, asi como de Perú y Argentina. Esta empresa pertenece a una transnacional de capital danés que a su vez hace parte de una corporación muy importante en Dinamarca.

\section{A manera de conclusion}

El concepto de región no es unívoco, en torno al cual pueda construirse un tipo ideal o una teoría general de las regiones como bien lo apunta De la Peña, sino que es un "concepto histórico, politético, cuyo significado se modifica por circunstancias de tiempo y lugar" (1991: 126). El sistema económico mundial está imbricado en regiones internacionales así como en regiones dentro de países pero la carencia de regulaciones que establezcan condiciones para la inversión transnacional pone a las economías locales en una situación precaria frente a las decisiones tomadas a nivel mundial como es el caso de la agroindustria del limón en el valle de Tecomán. Muchas decisiones no proceden de la población afectada como fue el caso del empuje proveniente de las políticas de ajuste adoptadas a partir de agosto de 1982, momento en que la gravedad de la acumulación de la deuda externa se hizo pública. El paquete de medidas que se adoptaron a continuación fue inspirado en las recomendaciones del FMI cuyo elemento esencial, tanto para México como para otros países afectados por la deuda y cuyas políticas de ajuste han seguido a un modelo parecido, es la apertura de la economía doméstica al exterior a través de la liberalización de las importaciones, la promoción de las exportaciones y de la competitividad a nivel internacional y el estímulo a la inversión extranjera, tanto productiva como financiera. En realidad este proceso llamado de "modernización" para México ha generado una transformación profunda de su economía, pasando de su orientación hacia el mercado dominante a una orientación hacia el exterior e intensificando de este modo su integración en la economía global.

\section{Referencias}

BRAUDEL, F. La historia y las ciencias sociales. Madrid: Alianza Editorial, 1984.

BRAVERMAN, H. Trabajo y Capital Monopolista. México: Editorial Nuestro Tiempo, 1987.

BUENO, C. "Una lectura antropológica sobre el sector informal”. En: Revista Nueva Antropología, v.XI, n.37. México: Instituto de Investigaciones Jurídicas/ UNAM, 1990.

BUENO, C. Flor de Andamio. Los oficios de la construcción de vivienda en la Ciudad de México. México: Ciesas, 1994. 
BURAWOY, M. Manufacturing Consent. Chicago: University of Chicago Press, 1979. BURAWOY, M. The Politics of Production. London: Verso, 1985.

DE LA PEÑA, G. "Los estudios regionales y la antropología social en México". En: HERRERO, P. (comp.). Región e Historia en México (1700-1850). México: Instituto de la Mora, 1991. p.123-162.

FINKEL, L. La organización social del trabajo. Madrid: Ediciones Pirámide, 1994.

LUPTON, T. On the shop floor - two studies on workshop organization and aout put. Oxford: Pergamon Press, 1963.

PALERM, A. Planificación regional y Reforma agraria. México: Universidad Iberoamericana/ Gernika, 1993.

ROBERREY, W. "Los campesinos y el mundo". En: Antropología Económica. México: Alianza Editorial, 1991.

SLOTKIN, J.S. From Field to Factory. Glencoe: New Industrial Employees Free Press, 1966.

TORRES, P. Before smoking. Social Relations involved in Tobacco Production in a Philippine Setting. Tesis de doctorado en Filosofia. Baltimore: Universidad de Johns Hopkins, 1986.

TORRES, P. “Antes de fumar. Análisis de la sociedad rural ilocana filipina a través del estudio del proceso de producción de tabacos claros". En: Nueva Antropología, n.39. México: Instituto de Investigaciones Jurídicas/ UNAM, 1991.

TORRES, P. "Nuevo capital transnacional en México: el caso Polaroid". En: Nueva Antropología, v. XI, n. 40. México: Instituto de Investigaciones Jurídicas/ UNAM, 1991. p. 23-35.

WALLERSTEIN, I. El modelo sistema mundial: la agricultura capitalista y los orígenes de la economía mundo europea en el siglo XVI. México: Siglo XXI, 1979.

Recebido em: 22/05/2012

Aprovado em: 25/07/2012 